\title{
LAS ANTOLOGÍAS POÉTICAS DE MUJERES EN LOS SIGLOS XXYXXI: RETROSPECTIVA Y COMENTARIO CRÍTICO
}

\author{
Marina Patrón Sánchez \\ Universidad Complutense de Madrid \\ https://doi.org/10.18778/8220-195-6.06
}

\section{Resumen}

Las antologías poéticas formadas en exclusiva por mujeres comenzaron a publicarse en el siglo XX como una forma de suplir el vacío que había en la historia literaria de España, a la par que se buscaba dar una mayor visibilidad a la obra poética de las escritoras. Esta práctica, que se ha extendido hasta el siglo XXI, es un arma de doble filo, debido a que por un lado ofrece un espacio para las poetas; pero, por el otro, el tratamiento que a veces reciben es injusto o insuficiente. Este trabajo realiza una retrospectiva sobre las más relevantes antologías de poesía escrita por mujeres, analizando su contenido, sus prólogos y el tratamiento que reciben las creadoras en ellas.

Palabras clave: Antologías poéticas, Mujeres poetas, Poesía española actual, Siglo XX, Siglo XXI.

Este trabajo surge de la pregunta: ¿Por qué se realizan y se siguen realizando antologías de poesía escrita por mujeres de una forma consciente y específica? La necesidad de estas obras es obvia: las poetas han tenido numerosas dificultades para acceder al mundo editorial, tanto por presiones sociales como empresariales. Es por esto por lo que este tipo de recopilaciones son un acto reivindicativo de la voz poética de una selección de autoras. Sin embargo, en muchos casos, esta reivindicación parece estar viciada, y no solo 
porque el concepto de antología, tal y como se ha conformado en los últimos años, se inserta en una concepción de la lectura equivalente a la comida rápida y preparada (Doce, 2005: 297); sino porque el tratamiento que reciben las autoras es muy distinto si el antólogo es hombre o mujer.

Mediante el análisis de varias antologías, desde 1943 hasta 2018, queremos mostrar las desigualdades que se producen en las mismas, así como reflexionar sobre su necesidad y su evolución. Para ello, nos hemos centrado en los prólogos, el número de poetas reunidas y el tratamiento que reciben las mismas basándonos en las notas biográficas y la inclusión o no de poéticas y fotos.

Nuestro análisis empieza con Cien años de poesía femenina española e hispanoamericana (1840-1940) (1943) de María Antonia Vidal. La inclusión de las poetas hispanoamericanas aparece justificada en el prólogo: "La exuberante floración de poetisas hispanoamericanas ofrece unas características del todo distintas de las nuestras", escribe Vidal; mientras ellas se desbordan en su sensibilidad, las españolas se mantienen tras "un velo de contención" (Vidal, 1943: 7). En el prólogo, Vidal descarta la comparación con la poesía escrita por hombres por considerar dicha comparación poco "ventajosa" para la mujer. A lo que añade: "Es indudable que todavía ninguna escritora, es posible que nunca ninguna escritora, llegue a la altura y profundidad, a la vez, de un gran escritor" (Vidal, 1943: 6). En el prólogo hace también un breve análisis de las poetas, pero no sabemos qué criterio ha seguido ni para antologarlas ni para reseñarlas. Al final de la antología incluye unas notas bio-bibliográficas de apenas un párrafo de extensión en las que a veces faltan incluso las fechas de nacimiento.

Un caso muy distinto es el de Carmen Conde y su Poesía española viviente, publicada por primera vez en 1950 y reimpresa en 1970 bajo el título Poesía femenina española (1939-1950). Esta antología, compuesta por veintiséis autoras, pretende reunir un abanico variado y diverso de las poetas de estos años. A la hora de justificar su selección, la escritora confiesa que: "En este tomo no figuran todas las poetisas, ni solamente las mejores; sí aquellas que conozco mejor, de las que poseo una información capaz de permitirme un juicio positivo, que me autoriza a incluirlas" (Conde, 
1970: 9). El tono del prólogo de esta antología es del todo opuesto al que veíamos en la anterior: Conde busca hacer una reivindicación no solo de las poetas, sino también de las demás creadoras que se estaban abriendo camino durante esos años. Defiende la originalidad de las obras, que escapan del "mimetismo a que estaba acostumbrada la anterior poesía femenina." Y señala que: "Lo más interesante [...] es que ha buscado y hallado sus temas en un vasto mundo de sensibilidad, que, hasta hoy, no era el de las poetisas" (Conde, 1970: 10). Su reivindicación al afirmar:

Hoy no sirve aquel adjetivo «femenino» para calificar desdeñosamente la obra poética de la mujer; pero tampoco ninguna de nosotras se sentiría halagada, sino más bien ofendida por la incomprensión, si se nos dijera que escribimos como hombres. No, como hombres no, como mujeres que saben plenamente, sí. (Conde, 1970: 14)

busca romper con la connotación negativa del término 'poetisa', con el que se solía denostar a las autoras, en un intento por equiparar a la obra de los y las poetas sin tener en cuenta su género. Todas las poetas aparecen acompañadas por una nota bio-bibliográfica, que, en varias ocasiones, está redactada por la propia autora.

El segundo volumen de la Antología femenina española (1950-1960) fue publicado en 1971. En este caso introduce una novedad respecto a la antología anterior: las notas críticas de Ángela Figuera al final de cada selección de poemas. Esta segunda antología supone la consagración de la presencia de las poetas en el panorama literario con una voz propia y distinta. Junto a la selección de poetas figura su bio-bibliografía, esta vez sí escritas por ellas mismas, y las notas críticas de Figuera, que son una breve reflexión sobre la poética de las autoras. Esta novedad es destacable, porque son las propias poetas las que hablan sobre sí mismas, convirtiéndose no solo en autoras o recopiladoras, sino también en críticas de la poesía escrita por sus compañeras.

En 1985 se publicó Las diosas blancas de Ramón Buenaventura. La antología, centrada en la joven poesía española, buscaba otorgar un lugar tanto a voces desconocidas como a otras más asentadas 
en el panorama poético. Sin embargo, el tono del antólogo, galante y paternalista, enturbia lo que podría haber sido un proyecto realmente importante e innovador. En el prólogo escribe:

Hago esta antología de poemas escritos por mujeres porque me apetece levantar un censo de amores posibles. [...] la única poesía que de verdad me gusta es la que escriben las mujeres. La otra, la de los hombres, es cosa de rivales o camaradas. Está muy bien: pero siempre me ha resultado molesto tener que reconocer que un tío es guapo (Buenaventura, 1985: 10).

Según esta afirmación, no está considerando a las mujeres ni como rivales ni como camaradas poéticos, sino como "amores posibles". Además, insiste en la diferencia entre la poesía escrita por mujeres y la escrita por hombres, denominándola "la otra".

A lo largo de todo el prólogo, el tono galante se va a mantener. Afirmaciones como "Es la mía una actitud sexual ante el arte" (Buenaventura, 1985: 10), van a venir apoyadas sobre referencias a la cópula con la Diosa Blanca, "las prostitutas sagradas que se someten a los sacerdotes”, y cómo la poesía surgió de la magia a través del sexo. También hace afirmaciones poco afortunadas, como:

Transcurren miles de años sin que ninguna mujer escriba nada hondamente femenino $^{1} \mathrm{y}$ al alcance de las entendederas viriles. Si esta afirmación les parece a ustedes demasiado radical, cítenme, por favor, una sola escritora que no haya traducido sus ideas y sentimientos al lenguaje de los machos. No hay (Buenaventura, 1985: 15).

¿Qué quiere decir con "hondamente femenino" o cuál es el "lenguaje de los machos"? Nos quedamos con la incógnita, porque no lo explica. En el prólogo no queda claro si la antología es un alegato en favor de la poesía escrita por mujeres o si es un gesto paternalista y seductor por parte de un antólogo que no sólo no

1 El destacado es suyo. 
las toma en serio, sino que además parece que su única intención es cortejarlas. Esto se puede apreciar también en los "comentarios críticos" que anteceden a la selección de las veintidós autoras. En ellos, además de incluir una foto y la bio-bibliografía, Buenaventura cuenta su impresión sobre las poetas: "Se ha vestido de trapillo para recibirme" dice de Margarita Arroyo o de Ana Rossetti, que "es un auténtico regalo para los pobres heteros, que tan escasos andamos de gratificación en los últimos decenios". Por todo esto, Buenaventura pierde la credibilidad: no es un antólogo hablando sobre poetas, sino un hombre hablando despectivamente sobre mujeres.

Radicalmente distinta es Ellas tienen la palabra (1995) de Noni Benegas y Jesús Munárriz. El estudio preliminar es un profundo recorrido por la historia de la literatura escrita por mujeres, haciendo énfasis en la poesía y en la injusta situación a la que se ha visto sometida, de lo que se deriva su desconocimiento. Benegas señala que la falta de visibilidad de las autoras es algo que se mantiene en la época actual, y por eso busca brindarles un espacio a estas cuarenta y una autoras que recoge. Su tono reivindicativo y sus argumentos bien estructurados no tienen nada que ver con lo ofrecido por Buenaventura, que parece una pantomima patriarcal frente al monumento necesario que es la antología de Benegas. Se debe destacar la diferencia en la presentación de las autoras: mientras que en Las Diosas Blancas era el propio Buenaventura el que reflexionaba sobre las poetas; en Ellas tienen la palabra, Benegas, haciendo honor a su título, les otorga a las autoras un espacio para que reflexionen sobre su poética a través de un cuestionario del que solo sabemos las respuestas.

En 1999, Emilio Miró publicó la antología de Poetisas del 27, una importante recopilación sobre las autoras de esta generación, acompañado de un generoso estudio preliminar, pero que solo da cobertura a la obra de cinco autoras: Concha Méndez, Rosa Chacel, Ernestina de Champourcín, Josefina de la Torre y Carmen Conde. Es interesante el recorrido que hace por las antologías que recogen a los poetas de la Generación del 27, señalando la escasa representación femenina en las mismas. Es una antología bastante completa, pero la justificación que da para incluir solo 
a cinco autoras es insuficiente: Miró señala que ellas fueron las más cercanas al círculo del 27 , pero en verdad ignora importantes nombres que después va a reivindicar Pepa Merlo en Peces en la tierra (2010). Esta antología se centra en la recuperación de veinte autoras de esta generación, entre las que se incluyen las cinco de Miró. Merlo ofrece además un extenso estudio introductorio en el que hace una revisión de la época histórica y sobre todo de la situación de la mujer. En su selección, prescinde de fotografías e incluye al final de la antología un apartado de vida y obras.

Otra antología es Ilimitada voz (2002) de José María Balcells, que reúne poemas de entre 1940 y 2002 de 149 autoras. Aquí vemos cómo los nombres se repiten: junto a las cinco del 27, volvemos a encontrarnos con Ana Rosetti, Chantal Maillard o Aurora Luque, lo que da cuenta de cómo se va constituyendo el canon de la poesía escrita por mujeres. En la "Introducción", Balcells vuelve a hacer un recorrido por la historia de la poesía escrita por mujeres hasta el albor del siglo XXI, destacando el "boom" de poetas que tuvo lugar durante los años 80 . La selección de poetas aparece sin foto y solo se indica la fecha de nacimiento. En voz alta. Las poetas de las generaciones de los 50 y los 70 (2007) de Sharon Keefe Ugalde se presenta a sí misma como la continuación de la obra de Benegas. En este caso se van a recoger aquellas autoras nacidas entre 1929 y 1949. La intención de este libro es iniciar un proceso dialógico que abra el discurso crítico-histórico a las perspectivas representadas en la poesía escrita por mujeres, dando cobertura a todas las décadas del siglo XX, por lo que junto a la nota bio-bibliográfica, incluye una poética y una extensa selección de poemas.

Una de las propuestas más interesantes es la Josefina de Andrés Argente y Rosa García Rayego en Di yo. Di tiempo. Poetas españolas contemporáneas. Ensayos y antología, publicada en 2005. La antología se centra en quince autoras nacidas entre 1925 y 1966, que son analizadas por poetas de su misma generación en breves ensayos incluidos junto a la selección de poemas. La intención de los ensayos es recoger y explicar el heterogéneo panorama de la poesía española escrita por mujeres desde los años 70 . Se vuelve a incidir en las nuevas corrientes poéticas, en 
la desigual representación de las mujeres en las antologías y en la lucha por la apropiación del lenguaje. En 2016, Rosa García Rayego, junto a Marisol Sánchez Gómez, ha publicado la antología 20 con 20. Diálogos con poetas españolas actuales. Al igual que en el caso de Conversaciones y poemas (1991) de Keefe Ugalde ${ }^{2}$, esta antología vuelve a incidir sobre lo adecuado de los diálogos para establecer el contexto personal y artístico de las autoras, así como su actitud poética y vital (Rayego, 2016: 17). También las breves notas biográficas, que anteceden cada diálogo en forma de ensayo, están escritas por las propias autoras. Las veinte poetas seleccionadas, que han nacido entre los años 50 y los 80 , conforman un grupo muy heterogéneo, pero como las antólogas defienden en la introducción:

nuestra selección es un intento de ofrecer un mapa de lecturas que aspira a dar visibilidad a unas poetas que nosotras consideramos esenciales y a reforzar la presencia de otras ya establecidas en un momento en el que la poesía escrita por mujeres se manifiesta con gran dinamismo en nuestro país (Rayego, 2016: 20).

El estudio de 2015 de María Rosal Con voz propia. Estudio y antología comentada de la poesía escrita por mujeres (1970-2005) es también otra vuelta de tuerca al género de las antologías, pues plantea un estudio histórico y una propuesta didáctica para que los profesores visibilicen a las autoras en las aulas. De entre las sesenta y nueve poetas que recoge, incluye catorce poemas comentados por las propias escritoras, lo que aporta una nueva interpretación sobre los mismos. Así pues, Con voz propia se convierte en

un documento útil de lectura, estudio y reflexión para subsanar las "lagunas" que hay en los libros de texto; ofrecer al alumnado una antología de poesía actual, escrita por autoras de

2 Esta antología fue pionera en la inclusión de las conversaciones con las autoras más allá de la recopilación de sus poemas, como una forma de conocer de primera mano su trayectoria artística y vital. 
nuestro tiempo que pueda fomentar la animación a la lectura [...] [e] indagar sobre cómo el lenguaje configura la visión del mundo y muy en particular la visión de las mujeres en la sociedad (Rosal, 2016: 13-14).

Con esta aspiración de contemporaneidad, la antología abarca desde la generación de los 60 hasta la década de los 80 y los 90 .

Sin embargo, el esfuerzo más titánico a la hora de documentar la historia de la poesía escrita por mujeres fue el de Luzmaría Jiménez Faro. En 1987 publicó el Panorama antológico de Poetisas Españolas (Siglos XV al XX), que fue el embrión de su magno proyecto Poetisas españolas. Antología general, dividida en cuatro tomos publicados a lo largo de varios años. El primero de ellos es de 1996 y hace un recorrido desde el siglo XV hasta el siglo XIX, reuniendo un total de veintinueve autoras. Es interesante la defensa que hace Jiménez Faro afirmando que: "La poesía -no cabe ya discusión a estas alturas- la escriben personas, no sexos". El segundo volumen, también de 1996, abarca el periodo de 1901 a 1939, con dieciocho autoras reunidas. El tercero, de 1998, se centra en el periodo de 1940 a 1975, con cincuenta autoras. Jiménez Faro afirma no atenerse a grupos generacionales que "no aportarían nada, pues la mayoría de ellas, por no decir casi todas, han sido olvidadas y no tenidas en cuenta en este tipo de trabajos" (Jiménez Faro, 1998: 7). Finalmente, el cuarto volumen, de 2002, recoge poemas publicados entre 1976 y 2001 e incluye un anexo conformado por varias tablas en las que analiza la presencia de la mujer en antologías publicadas desde 1934 hasta 2001, evidenciando su escasa presencia. En este volumen se recogem 128 poetas, incluyendo también un listado con autoras que no ha publicado, pero que no quiere dejar de mencionar.

Una vez terminado nuestro análisis podemos constatar cómo estas antologías están ayudando a configurar un canon de escritoras, sobre todo a partir de los años 80 . Desde la primera antología hasta la última hemos visto cómo el género ha ido evolucionando e incorporando innovaciones, como las reseñas críticas, las entrevistas con las autoras o la inclusión de poéticas, dando mayor importancia a su voz. Si comparamos las antologías hechas por 
mujeres frente a las realizadas por hombres, las primeras son más partidarias de incluir espacios de expresión para las autoras, así como estudios en los que repasan la historia literaria de las mujeres, como forma de rastrear una tradición literaria femenina. Las antólogas son más conscientes de la reivindicación de la poesía escrita por sus compañeras, pero también algunos antólogos se suman a este esfuerzo. Hay un deseo recurrente en muchas antólogas, desde Carmen Conde hasta Noni Benegas, que defienden una poesía sin distincióAn de género y unas antologías que incluyan a poetas de ambos sexos. Sorprende constatar cómo Noni Benegas en 1995 o Barcells en 2001 insisten en que la atención a la poesía escrita por mujeres es insuficiente, y que, si figuran en las antologías generales, lo hacen con la cuota mínima. Si en algo coinciden la mayoría de los antólogos es en la esperanza de que llegue el día en que no haya necesidad de hacer antologías de mujeres. Sin embargo, aún queda mucho camino por delante.

\section{Bibliografía}

Andrés Argente, J. de; García Rayego, R. (eds.) (2005). Di yo. Di tiempo. Poetas españolas contemporáneas. Ensayos y antología. Madrid: Devenir.

Balcells, J.M. (ed.) (2003). Ilimitada voz. Antología de poetas españolas 1940-2002. Cádiz: Servicio de Publicaciones de la Universidad de Cádiz.

Benegas, N.; Munárriz, J. (eds.) (1997). Ellas tienen la palabra. Dos décadas de poesía española. Madrid: Hiperión.

Buenaventura, R. (ed.) (1985). Antología de la joven poesía española escrita por mujeres. Madrid: Hiperión.

Conde, C. (ed.) (1970). Poesía femenina española (1939-1950). Barcelona: Editorial Bruguera.

Conde, C. (ed.) (1971). Poesía femenina española (1950-1960). Barcelona: Editorial Bruguera.

Doce, J. (2005). "Poesía española hoy: de la arbitrariedad a la domesticación”, en A. Sánchez Robayna y J. Doce (eds.). Poesía hispánica contemporánea. Ensayos y poemas, 285-308. Barcelona: Galaxia Gutemberg. 
García, R., Rosa; Sánchez Gómez, M. (eds.) (2016). 20 con 20. Diálogos con poetas españolas actuales. Madrid: Huerga y Fierro Editores.

Jiménez Faro, L. (ed.) (1996-2002). Poetisas españolas. Antología general. Tomo I: hasta 1900; Tomo II: de 1901 a 1939; Tomo III: de 1940 a 1975; Tomo IV: de 1976 a 2001. Madrid: Torremozas.

Keefe Ugalde, S. (ed.) (1991). Conversaciones y poemas. La nueva poesía femenina española en castellano. Madrid: Siglo XXI Editores.

Keefe Ugalde, S. (ed.) (2007). En voz alta. Los poetas de las generaciones de los 50 y los 70. Antología. Madrid: Hiperión.

Merlo, P. (ed.) (2010). Peces en la tierra. Antología de mujeres poetas en torno a la Generación del 27. Sevilla: Vandalia Fundación José Manuel Lara.

Miró, E. (ed.) (1999). Antología de poetisas del 27. Madrid: Castalia.

Rosal, M. (ed.) (2016). Con voz propia. Estudio y antología comentada de la poesía escrita por mujeres (1970-2005). Córdoba: Editorial Renacimiento.

Vidal, M.A. (ed.) (1943). Cien años de poesía femenina española e hispanoamericana 1840-1940. Barcelona: Editorial Olimpo. 